\title{
ÎNSEMNĂRI PE CĂRṬILE DE CULT DIN CRIȘANA (SECOLELE XVII-XVIII). DE LA PARATEXT LA FILE DE ISTORIE
}

\author{
Lia-Ramona VLAD (LUPU)*
}

\begin{abstract}
Notes on cult books in Crişana region (XVII-XVIII centuries). From paratext to history files ${ }^{1}$. The period, subject of this study, was a particularly tormented one for the history of Transylvania and consequently for Crişana region. On a background dominated by the desire for ideological affirmation, ethnicities, the book is portrayed as a companion for a bright, effervescent and brighter century then the previous ones. The clear proof that authentic values overcame time is the fact that, in all of Crişurilor region, thousands of prints and manuscripts are a testimony of the Romanian culture in these places and illustrates the central points of Romanian enlightenment. Another important aspect, which provides books withdocumentary value, is represented by the notes on their files. They often provide historical, religious, literary and artistic data of great importance. Based on these coordinates I'll study here, trying to pointing out the importance of these notes through the data analysis they provide, but also, from a linguistic point of view, the notes represent sequences that make up a communicational unity with informative role. Another side that will be pursued is that of the information they convey, because written down in books by people, the marginal notes tell us a lot about their lives and past, leading to forms of mentalities expressions through books and through the book universe which it shapes anywhere it is present. Also it should not be forgotten that notes offer the most diverse testimonies from books destination, their role in enlightenment, to the names of the initiates that shared its teachings. Last but not least, because it assumes parts of individual and collective memory e.g. "to be
\end{abstract}

“PhD Student, Faculty of Orthodox Teology „Justinian Patriarch”, at University of Bucharest, Bucharest, Romania.

${ }^{1}$ Studiu redactat sub îndrumarea Pr. Prof. Univ. Dr. Mihail-Simion Săsăujan, care şi-a exprimat acordul pentru publicare. 
known" formulas, the information they contain constitute existential landmarks that lead to an unrepeatable reality.

Keywords: period, manuscripts, books, religious, notes.

\section{Introducere}

Perioada care face obiectul prezentului studiu, a fost una deosebit de frământată pentru istoria Transilvaniei şi implicit a regiunii geografice a Crişanei. În contextul istoric dominat de dorința de afirmare ideologică a națiunilor s-a profilat cartea ca însoțitor al unui secol efervescent şi mai luminat decât cele precedente. Numeroasele tipărituri şi manuscrise din această parte de țară sunt mărturie a culturii româneşti şi ilustrează coordonatele locale ale iluminismului românesc.

Tipăriturile şi manuscrisele, care au circulat în Crișana în secolele XVII-XVIII, s-au bucurat de grija specială a comunităților parohiale, fără de care noi nu am fi putut intra în posesia lor. Ele vin să dea mărturie despre două veacuri de istorie şi spiritualitate creștină şi să ateste dorințele românilor de aici de a-și trăi viața înconjurați de cărți bisericești, acestea având nu doar un rol primar liturgic, ci și unul cultural-social esențial pentru cotidianul colectiv din acele timpuri.

Unul dintre aspectele cele mai importante, care oferă cărților vechi liturgice valoare documentară, este reprezentat de însemnările existente pe filele lor.

Fenomenul generat de însemnările de pe filele manuscriselor şi a cărților are o vechime considerabilă, iar amploarea lui a dat naştere unor categorii speciale de surse istorice sugestive în vederea cunoaşterii unei epoci. Valoarea însemnărilor ca sursă istorică depinde de timp şi spaţiu, de specificul unei societăți într-o anumită etapă, de raportarea la numărul şi valoarea altor surse istorice ${ }^{2}$.

Spre exemplu, unele particularități religioase, istorice, sociale și culturale ale societății româneşti din Crişana secolelor XVII-XVIII, apar evidențiate în cadrul însemnărilor de pe cărțile care au circulat pe acest teritoriu. Chiar dacă datele prezentate sunt uneori lapidare, ele rămân mărturii documentare de valoare în conturarea istoriei locale.

2 Marieta ADAM CHIPER, Vechi însemnări româneşti ca izvor istoric, Bucureşti, Edit. Silex, 1996, p. 11. 
Însemnările prezintă o arie de cercetare care poate completa tabloul istoriografic social, economic şi cultural al timpului. Chiar dacă se caracterizează prin subiectivism, prezența lor în structura cărții, însoțind textul în decursul timpului, invită la descifrare, mai ales pentru de a vedea ceea ce vor să transmită dincolo de textul scris.

De asemenea, însemnările pot fi considerate izvoare primare pentru studiile antropologice, deoarece ambii, atât omul cât şi cartea, sunt călători nedespărțiți în trecerea prin această lume şi viață. Trecute pe marginea cărților de către oameni, aceste însemnări spun multe despre trecutul şi viețile acestora, conducând şi la forme de exprimare a mentalităţilor prin carte şi prin universul livresc pe care cartea îl conturează oriunde este prezentă. Însemnările creează un liant între oamenii de mult dispăruți şi sfera preocupărilor acestora, perceput distinctiv în funcție de potențialul intelectual care le permitea să observe evenimentele trăite. Ele dezvăluie o lume din viața de altădată care se zăreşte palid dincolo de eşafodajul textului și recompune trăiri individuale, familiale, comunitare.

Autorii însemnărilor sunt buni observatori ai realităților pe care le consemnează într-o manieră proprie prin date, care, deşi nu reuşesc tot timpul să redea actul istoric în ansamblul său, mijlocesc contactul cu viața cotidiană, iar reunite devin un imens jurnal colectiv al istoriei noastre, o istorie consemnată de cei mici şi neînsemnați.

În lumina însemnărilor de pe vechile cărți de cult românești se conturează dimensiunea culturală şi morală a cărții, care în perioada amintită se bucura de o considerație deosebită, existând convingerea că şi generațiile viitoare vor nutri aceeaşi grijă față de carte - o adevărată punte de legătură între oameni, spațiu şi timp. Exista certitudinea că însemnările, odată trecute pe filele cărților, deveneau nu doar registre biografice, locuri pentru consemnarea evenimentelor şi fenomenelor sau de notare a numelui posesorului, ci că ele urmau să străbată timpul şi că nu vor fi uitate, fapt întărit prin formule specifice, devenite laitmotiv, „să se ştie că...”, ,să se ştie când...”.

Nu în ultimul rând, pentru că ị̂i asumă părți ale memoriei colective şi individuale în formule de tipul „ca să se ştie”, însemnările trebuie privite şi ca repere existențiale care exprimă momente irepetabile, frânturi 
de suflet, ferecate în cuvinte, care aduc mai aproape de noi figurile micilor cronicari.

În studiul prezent propun o analiză tematică a unora dintre însemnările identificate de cunoscutul cercetător Florian Dudaş pe cărțile de cult românești care au circulat în aria geografică a Țării Bihorului, în secolele XVII-XVIII ${ }^{3}$ și o înțelegere contextuală istorică - culturală a acestora.

\section{Semnificația lingvistică a însemnărilor de pe cărțile de cult: paratexte care însoțesc și relaționează cu textul de bază al cărții}

Din punct de vedere lingvistic, însemnările de pe vechile cărți de cult pot fi definite ca secvențe care alcătuiesc o unitate comunicațională cu rol informativ şi îndeplinesc cele şapte standarde ale textului: coeziune, coerență, intenționalitate, acceptabilitate, informaționalitate, situaționalitate şi intertextualitate ${ }^{4}$.

Datorită faptului că se înscriu în categoria corpusurilor textuale care se intersectează cu textul de bază al cărții sau al manuscrisului, însemnările pot fi considerate paratexte, adică producții discursive care însoțesc textul cărții și care sunt investite cu anumite grade de reprezentare a cărții actualizate odată cu lecturarea şi interpretarea ${ }^{5}$.

Paratextul nu face altceva decât să înconjoare textul, să îl prelungească cu scopul de a-l prezenta, de a-i asigura materialitatea, receptarea şi consumul în forma cărții ${ }^{6}$.

Fiecare însemnare intervine prin nivelul şi specificul său de comunicare atât în constituirea structurii unei cărți, cât şi în mecanismul receptării ei, prin faptul că relaționează cu textul de bază, îl exploatează pentru a-1 pune în valoare, pentru a informa, pentru a convinge şi a argumenta?

${ }^{3}$ Florian DuDAș, Vechi tipărituri româneşti din Ţara Bihorului, I, Timişoara, Edit. de Vest, 2007.

${ }^{4}$ Paul CORnEA, Introducere în teoria lecturii, Bucureşti, Edit. Minerva, p. 15.

${ }^{5}$ Philippe LANE, Periferia textului, Iaşi, Edit. Institutul European, 2007, p. 11.

${ }^{6}$ Ibidem, p. 15.

7 Teodora FîNTÎNARU, Insemnări pe cărți ca formă de paratextualitate, disponibil pe: http:// www.diacronia.ro>indexig>details (accesat la: 26.06.2019). 
Uneori, relaționarea unor însemnări cu textul de bază al cărții este directă, sub forma unui comentariu care face trimitere la acesta. Un exemplu concludent este o însemnare de pe fila 179 a exemplarului de la Brustuei a unui Evangheliar românesc (Braşov, 1561): „Îmblamu toți creştinii să ceremu Duhul sf(â)ntu, cu elu depreună credență, dere(a)ptă, când vuvomu noui trece di(în) această lume (...)".8.

Alteori, această relaționare este indirectă, fără aprecieri directe asupra conținutului cărții, oferind informații privitoare la proprietarii cărților sau la eforturile de achiziționare ale acestora. Un exemplu în acest sens este însemnarea din 12 martie 1783 de pe exemplarul copistului peregrin Ioan Muncăceanul al Cărții româneşti de învățatură - Cazania mitropolitului Varlaam (Iaşi, 1643): „Această Cazanie o am cumpărat eu, Popa Iova din Somoşcheş, cu 3 căbele şi jumătate de grău de la Pavel Popovici, în 1783, martie 12"'. In acelaşi exemplar există pe filele 32 şi 33 o altă însemnare legată de prețul de achiziție al cărții: „Eu, Vasile Popovici din Bochia, am dat pe Cazania aceasta 11 zloți, în Sibiu, în anul 1809 de la Hristos" "10. Din exemplarul de la Bixad al Cazaniei aflăm de pe filele 141-151 că: „Această carte, anume Ucitelnă, o au cunpărat Dănilă din Bicsad pre ce parte au luat din Tur [de] (l)a soro-sa, că auluat numai 20 de florinți, iară alalți 15 florinți am dat eu, PopaIacob, a neştor oamini din neste serecuste a lui Burduc Ioan 9 florinți şi a lui Băieş Grigor(e) şi a alt(o)r oameni şi au pusu în besea(ri)ca Bicsadului păntru păcatele şi a tot rodul lor. D(u)mnezeu Svinț(i) Sa se-i scrie în Cartea vieței, se hie în număr cu înjerii”. Exemplarul de la Coroi are o însemnare pe filele 2-11 din care reiese că: ,...eu, protopopul Dimitrie... din Pocei a am dat în mâna lui Popovici Mihai, în vidicul Beliului, din Coroi, ca să...cu zece florinți (...)"'11.

Ultimul tip de relaționare vizează o înscriere a însemnării în alt registru, fără legătură cu textul de bază. Chiar dacă acest tip de însemnări nu oferă informații directe sau indirecte despre cartea suport care le găzduieşte, ele descriu crâmpeie ale vieții sociale și cotidiene a oamenilor dintr-un anumit moment istoric determinate, spre exemplu, de fenomene

${ }^{8}$ Florian DuDAŞ, Vechi tipărituri româneşti din Ţara Bihorului, I, p. 16.

${ }^{9}$ Ibidem, p. 43.

${ }^{10}$ Ibidem, p. 45.

${ }^{11}$ Ibidem, p. 55. 
meteorologice, etc. Astfel, ele sunt dependente de textul de bază în lipsa căruia nu se pot reprezenta şi nu-şi pot constitui o identitate proprie, dar nu explică nimic din conținutul acestuia, nu sunt prelungiri semantice care să ajute cititorul în decodarea lui şi încalcă, în acest fel, regulile impuse de paratextualitate. În acest sens avem însemnarea exemplarului de la Oradea al Paliei de la Orăştie (1582), de pe fila 3: „Annul 1770, ghenuarie în 7 zile, s-au arătat ceață roşie, ca şi sângele, pe ceriu, de sara pănă la miazănoaptea” sau pe cea de pe fila 2: „An(ul) 1795. Toată iarna a fost un braț de fân [cu]8 florinți, o vacă [cu] 6 florinți, 1 porc mare [cu] 1 florinț, o pâine [cu] 4 husăşi, până la seceriş. Şi în anul acela a fost o iarnă cât nu se poate spune tăria şi cruzimea ei" ${ }^{\prime 12}$.

\section{2. Însemnările de pe vechile cărți de cult: conținut și semnificație}

Membrii comunităților, martori ai vremurilor de mult apuse, au ținut să consemneze evenimentele semnificative din viaţa lor, iar locul cel mai potrivit pentru a face acest lucru a fost pe filele cărților, singurele obiecte demne de a păstra memoria colectivă. Însemnările făcute de diferiţi preoţi ori cărturari îmbogăţesc considerabil istoria cărţii vechi, făcând legătura cu circulaţia ei, dar şi cu evenimentele politice, religioase sau sociale despre care cartea a rămas astăzi singurul martor.

Însemnările existente prezintă informații despre autorii însemnărilor, proprietarii cărților, donații de cărți de cult, aspecte biografice, vizitații canonice ale episcopilor în eparhiile lor, reparații ale locașurilor de cult, evenimente istorice, fenomene meteorologice și epidemii care s-au abătut asupra comunităților, etc.

\section{Autorii însemnărilor}

Însemnările de pe filele cărților furnizează informații importante despre cei care le-au întocmit. De multe ori, ele aveau un autor moral şi unul propriu-zis, copistul, care întocmea textul pe carte la cerere. Este vorba despre copiştii de mănăstire, dieci, legători de carte care înainte de toate erau cititori, pentru ei lectura fiind obligatorie.

\section{Proprietarii cărților}

Exemplarul de la Homorog al Cazaniei lui Varlaam (Iași, 1643) conține o astfel de însemnare pe fila 327: „Eu, Popa Ion, am scris că

12 Ibidem, p. 32. 
această carte este a lui Popa Ion Sărăcsău unitu. Încă nu ştie scrie bine, că acum învață" "13.

\section{Donații de cărți întru pomenirea veșnică a donatorului}

$\mathrm{Cu}$ trecerea timpului, cartea a fost mai mult decât un obiect material, ea a reprezentat un liant comunitar, fapt dovedit de numeroasele danii de cărți. Însemnările menționează, adeseori, donațiile de cărți făcute de unii credincioși mai înstăriți anumitor biserici cu scopul de a fi pomeniți la sfintele altare după trecerea lor din această viață pământească.

Un astfel de exemplu este Cazania lui Varlaam (Iaşi, 1643), exemplarul de la Lugaşul de Sus, care conține pe fila 198, o consemnare de donație: „Eu, Lupul Zaharie din sat(ul) Bârgău, dat-am această sfântă Evanghelie uceteală la biserica din Căndreni, care am cumpărat pe banii mei drepți şi o am dat pomană pentru sufletul meu şi a părinţilor mei şi [a] soțului meu şi a feciorilor mei. Şi o am dat ca să fie [a] sfintei biserici în veci, unde este hramul Sfântului Nicolai, iară cine ar fura-o (...) 1781, fevr(uarie) 28 zile" 14 .

Pe filele 138-139 ale exemplarului din Cotiglet al unui Octoih (Bucureşti, 1720), autorul consemnează: ,Să să ştie [că] această sf(â)ntă carte, anume Octoih, o au cumpărat Ioan Jurca pentru sufletul părinților şi al lui şi a fimei(i) BănaMariaşi [să] fi(e) pomanăşi î(i) dată besereci(i) la Hidişel Nand"15.

O însemnare asemănătoare apare pe exemplarul de la Lugaşul de Sus al Cazaniei lui Varlaam (Iași, 1643): „Eu, Lupul Zaharie din sat(ul) Bârgău, dat-am această sfântă Evanghelie uceteală la biserica din Căndreni (...)"'16.

Pe fila 465 a exemplarului din Ciutelec al Îndreptării legii (Târgovişte, 1652) este consemnată donaţia unui membru ecleziastic: "Scriueu, Udriştediac, la tine frate Popa Teodor cum aceasta să şti şi să nu să uite cum că această carte o dau ție să o duci la frați(i) de(n) Ardeal, această carte pre limba rumănească (...)" $)^{\text {17 }}$.

\footnotetext{
13 Ibidem, p. 61.

${ }^{14}$ Ibidem, p. 65.

15 Ibidem, p. 255.

${ }^{16}$ Ibidem, p. 65.

${ }^{17}$ Ibidem, p. 113.
} 
Alte însemnări vorbesc despre actul de donație dar și despre scopul acesteia - acela de fi făcute rugăciuni și pomeniri permanente pentru sufletul donatorului răposat. Într-un exemplar de la Oradea al celor Şapte Taine (Iași, 1644): „Această s(fântă) Pravilă este a lui Ioan Sevăntăi, o au lăsat pomană moşul meu tatăl maicii Tecla, să-i fac pomenire la s(fântul) jărvelnic "18.

Aspecte biografice (nașteri, botezuri, căsătorii, decese, etc.)

Aria însemnărilor cuprinde şi cronici sumare de familie sau comunitare. Pe filele unui Chiriacodromion (Alba Iulia, 1699) exemplarul din Groşeni, apare o însemnare din anul 1719, care atestă că „(...) Ioan (s-)au născut în luna noiemvrie 26 de zile văleat... şi când l-au prins la oaste s-au strâns 7 preoți de au... cumpărat, în ziua îngerilor Mihail ş Gavr(i)il. Veleat 1719",19.

Fila 63 a exemplarului de la Oradea a Mărgăritarelor Sf. Ioan Gurăde-Aur (București, 1691) cuprinde următoarea însemnare din anul 1729: „, Când au fost anul 1729 s-au născut Ion, pruncul lui Gheorghe... "20.

Un eveniment nefericit este consemnat pe fila 235 a exemplarului de la Vaşcău al Evangheliei învățătoare (Mănăstirea Dealu, 1644). Din însemnarea ce datează din anul 1646, aflăm ,,când au murit de ciumă. Leata G(ospod)nea H(ristove)"21.

Filele unui Antologhion (Râmnic, 1705), exemplarul de la Mizieş surprind următorul text: „Să se ştie când au prins hărămia ce(a)de lotru, pă Naşu Dundaşu din Cărpinetu, în luna august 10 zi(le)"’22.

Un Liturghier (Târgovişte, 1713), exemplarul de la Oradea, conține în paginile lui o însemnare ce are menirea de a marca pentru eternitate un eveniment semnificativ pentru autorul ei: ,S Să se ştie când s-au însurat Ioan Popovici, în luna fevruarie în unsprăzece zile" 23 .

\section{Vizitații canonice ale episcopilor în eparhiile lor}

Protopopul Simion consemnează pe fila 148 a exemplarului de la Oradea al Mărgăritarelor Sf. Ioan Gură-de-Aur (Bucureşti, 1691) vizita episcopului Sinesie Jivanovici al Aradului: „Amu scriseu, protopop(ul)

\footnotetext{
18 Ibidem, p. 85.

${ }^{19}$ Ibidem, p. 196.

${ }^{20}$ Ibidem, p. 159.

${ }^{21}$ Ibidem, p. 83.

22 Ibidem, p. 244.

${ }^{23}$ Ibidem, p. 249.
} 
Sim(i)on din Peştişu când (...) au umblat vlădica Sinesie Jivanovici în vizitație în varmeje(a) Bihării şi înpostul lui Simpetru au umblat pe Crişul Repede şi înzu(a) de Simpetru au fo(st) în Lugajelu. 1759"24.

\section{Reparații ale locașurilor de cult}

Pe fila 587 a Îndreptarului legii (Târgovişte, 1652), exemplarul de la Leheceni şi Cărpinet, autorul consemnează amănunte privitoare la reparaţia bisericii: „Eu, Popa Avram, avui bai cu satul Cărpenet şi satul Leheceni să acopăr besereca, că mă ploaie în ea când slujesc şi ziseră să [o] acoperim şi noi, popii..." 25 .

\section{Evenimente istorice}

Unele însemnări redau aspecte istorice, urmărind reconstituirea unor situații politice, economice sau sociale prin confirmarea şi completarea celorlalte surse istorice. Chiar dacă nu oferă informații istorice majore, aceste însemnări furnizează întregiri şi precizări care nu se regăsesc în alte izvoare şi reflectă, pe de altă parte, impactul provocat de acele evenimente asupra membrilor comunitătilor de credincioși.

Evenimentul istoric care se conturează în oglinda însemnărilor, este unul apăsător, trăit în mod direct.

O însemnare scrisă la începutul secolului al XVIII-lea, pe un exemplar al Chiriacodromionului (Alba Iulia, 1699) consemnează ocuparea Oradiei de către habsburgi (1692): „Când au luat Oradea nemții, ani de la naşterea lui H(risto)s 1692 şi scăpă Racolţa de la Beciu şi se duse sub Sătmar în 1703"'26.

Despre eliberarea Timişoarei de sub turci (1718) consemnează exemplarul de la Oradea al Noului Testament (Alba Iulia, 1648), care pe fila 6 are următoarea însemnare: ,Scris-am eu, Pop(a) Mihai, Scris-am când au luat nemții Temeşoara de l(a) turci, în anul de l(a) H(risto)s 1718, în luna lui octombrie în 8 zil(e)",27.

Răscoala condusă de Pero Seghedinaț (1735) este consemnată în exemplarul din Chişineu Criş al unei Evanghelii (Bucureşti, 1723): „Să se ştie cându au fost curuți la Herdeahigiu (Pădureni) de iau tăiat sârbii în 1735 atunci au murit popa Iancu din Comloş şi Tule Toaderă din Valea

${ }^{24}$ Ibidem, p. 160.

${ }^{25}$ Ibidem, p. 115.

${ }^{26}$ Ibidem, p. 196.

${ }^{27}$ Ibidem, p. 102. 
Neagră (...)”, dar şi pe filele unui Molitvelnic: „Nemții au luat Timişoara 1717, Robitau tătarii țara Hălmagiului şi iau tăiat curuți la Hărdajul Serbici şi au pierit căpitanul din Ineu Meletie. Scrisam au Ioan Popovici Muncăanul când am locuit în satul Dieci 1760 mai 20”28.

O însemnare dintr-un exemplar de la Oradea al Psaltirii în versuri (Iași, 1673) o mentionează pe Maria Tereza: „În anii 1742, în luna lui fervruarie, s-au arătat pe Ceriu [o] stea şi nu era ca alte stele, ce avea din stea înainte sul luminat ca o suliță. Şi aceasta a fost întru întie an a crăirei, ce era craiu Ţării Ungureşti, Mariia Terezia, fata lui Carolu şi al şasele, împăratului Romei" ${ }^{29}$.

Pe exemplarul de la Voievozi a Cazaniei lui Varlaam - Carte românească de învăţătură (Iaşi, 1643), fila 218, apare însemnarea: „Scrisam eu, Popa Lup din varmeghia Sătmariului, [din] sat(ul) pre nume Țicău, în anul 1774, luna iunie 27, la [sărbătoarea] Sf[â]ntului Mare Mucenic Pantelimon, in zilele Craiesii Maria [Tereza]"30.

Exemplarul de la Oradea al Psaltirii în versuri (Iași, 1673) conține pe fila 165 o însemnare care vorbește despre moartea Mariei Tereza: „Anul 1778, de când au umblat lăcustele întie. Iară când s-au răposat Mariea Terezia au fost anii 1781"31.

Răscoala lui Horea (1784) este un alt eveniment istoric consemnat pe fila 147 a exemplarului din Corbeşti a Noului Testament (Bălgrad, 1648): „Când au ars curțile domnilor din Ţara Ardealului şi în Ţara Austriacă au fost ano 1785” sau într-un Triod (Rîmnic, 1782): „La anul 1786 au vinit robii trăgând şăicile pă Murăş, a decă acei, care au avut să otrăvească pe impăratu, mitropolitul ungurilor şi grofi, cei mari, şi veți istorisi, şi la toți au pus lanțuri în Minişs şi păgrumaz pănă au murit”"32.

\section{Fenomene meteorologice și epidemii}

O altă categorie de însemnări vizează informații despre fenomene meteorologice neobișnuite și despre răspândirea în cadrul comunităţii parohiale a unor epidemii.

${ }^{28}$ Elena Rodica COLTA, „Însemnări de pe cărți vechi româneşti, documente ale veacurilor trecute", în Ziridava, 1979, p. 1072.

${ }^{29}$ Florian DuDAș, Vechi tipărituri româneşti din Ţara Bihorului, I, p. 133.

${ }^{30}$ Ibidem, p. 61.

${ }^{31}$ Ibidem, p. 131.

32 Elena Rodica CoLTA, „Însemnări de pe cărți vechi româneşti, documente ale veacurilor trecute", p. 1073. 
Astfel, aflăm că: ,În anul 1771, iulie 11 zile, au fost o ploaie atâta de rece şi frig iera, cât multă marhă au murit pe câmp, de răceală şi frigul care le era" - fila 3, exemplarul de la Oradea al Paliei de la Orăştie (1582) sau că: „Anul 1782 , avgust în 10 zile, au venit o mulțime de lăcuste, şi atâtea era(u) la pădure(a) de [la] Sent Ianoş cât mulți copaci s-au dejghinat de greotatea lăcustelor" 33 .

Este sugestivă însemnarea de pe fila 2 a Paliei de la Orăştie (1582), exemplarul de la Oradea, care prezintă cutremurul din anul 1786: „Anul 1786, septemvrie în 8 zile, sara la 7 ceasuri, s-au arătat pe ceriu despre amiazăzi, pe subt nor, ca şi Soarele şi s-au luminat pe tot locul ca de foc, s-au cutremurat pământul la Orade(a) Mare"34.

\section{Concluzii}

Însemnările înscrise pe marginile cărților de cult românești folosite în comunitățile parohiale din Țara Crișurilor, în secolele XVII-XVIII, constituie adevărate trăiri de viață și de sentimente umane, fapt ce le deosebeşte de stereotipia documentelor de cancelarie, care, foarte rar, lasă loc exprimării spontane a trăirilor celui ce le redactează. Pentru că stilul lor de redactare nu se supune unor canoane riguroase sau unor formule rigide de cancelarie, ajung până la noi spiritul şi trăirile unor oameni care prin însemnările lor au confirmat importanța scrisului. Un număr mare de preoți, dascăli sau țărani simpli au semnat pe filele cărților şi ale vechilor manuscrise, spre aducere aminte, dovedind astfel, urmaşilor lor, rolul cărții în luminarea poporului. Însemnările arată sugestiv destinația cărții, dovedind folosirea ei necontenită în decursul timpului încadrulc omunităţilor româneşti pentru învățătură creștină şi lectură ${ }^{35}$.

\section{Referinţe bibliografice:}

1. ADAM CHIPER, Marieta, Vechi însemnări româneşti ca izvor istoric, Bucureşti, Edit. Silex, 1996;

2. ColTA, Elena Rodica, ,Însemnări de pe cărți vechi românești, documente ale veacurilor trecute", în Ziridava, 1979, p. 1059-1081;

${ }^{33}$ Florian DuDAș, Vechi tipărituri româneşti din Ţara Bihorului, I, p. 32.

${ }^{34}$ Ibidem, p. 32.

${ }^{35}$ Florian DuDAș, Manuscrisele româneşti medievale din Crişana, Timişoara, Edit. Facla, 1986, p. 169. 
3. CoRnEA, Paul, Introducere în teoria lecturii, Bucureşti, Edit. Minerva, 1998 ;

4. DUDAŞ, Florian, Vechi tipărituri românești din Tara Bihorului, I, Timişoara, Edit. de Vest, 2007;

5. DuDAŞ, Florian, Manuscrisele româneşti medievale din Crişsana, Timişoara, Edit. Facla, 1986;

6. FÎNTÎNARU, Teodora, Insemnări pe cărți ca formă de paratextualitate, disponibil pe: http://www.diacronia.ro>indexig>details (accesat la: 26.06.2019);

7. LANE, Philippe, Periferia textului, Iaşi, Edit. Institutului European, 2007;

8. ȘTREMPEL, Gabriel, Copiști de manuscrise românești până la 1800, Bucureşti, Edit. Academiei RPR, 1959. 